\title{
La publicación y difusión científica en tiempos de pandemia por el COVID-19
}

\author{
Scientific Publication and Dissemination in Times of a COVID-19 Pandemic
}

\section{Publicação científica e divulgação em tempos de pandemia de COVID-19}

Eliana Guzmán-Useche

Universidad de Los Andes

Mérida, Venezuela

eliana@ula.ve

iD https://orcid.org/0000-0001-7253-670X

Fernando Rodríguez-Contreras

Universidad Autónoma del Estado de México

Estado de México, México

fernando.rodriguez@redalyc.org

https://orcid.org/0000-0003-0752-7705

Resumen: Ante la actual pandemia mundial, la producción y difusión científica ha permitido crear bases de conocimiento confiables, en búsqueda de propósitos comunes: erradicar el virus, evitar nuevos contagios y determinar estrategias de salud pública para el futuro inmediato.

Palabras claves: Publicación científica; COVID-19; Acceso Abierto; base de conocimiento.

Abstract: In this global pandemic, scientific production and dissemination has allowed the creation of reliable knowledge bases, in search of common purposes: eradicate the virus, prevent new infections and determine public health strategies for the immediate future.

Keywords: Scientific publication; COVID-19; Open Access; knowledge database.

Resumo: Nesta situação de pandemia global, a produção e divulgação científica tem permitido a criação de bases de conhecimento confráveis, em busca de objetivos comuns: erradicar o vírus, prevenir novas infecções e determinar estratégias de saúde pública para o futuro imediato.

Palavras-chave: Publicação científica; COVID-19; Acesso Aberto; base de conhecimento.

Recibido: 29/08/2020 Aceptado: 05/10/2020 
https://doi.org/10.15359/ree.24-S.6

https://www.revistas.una.ac.cr/index.php/educare

educare@una.ac.cr

\section{Introducción}

Personas investigadoras y científicas de todo el mundo han realizado aportes desde su área de conocimiento, estableciendo nuevos parámetros en diferentes aspectos del quehacer diario, especialmente en la salud. Quienes investigan en medicina, biología y epidemiología están bajo la lupa constante, ya que el mundo entero está a la expectativa sobre la tan apreciada vacuna para lograr la inmunidad necesaria que proteja a la población del SARS-CoV-2.

Desde el inicio de la pandemia se ha observado la evolución de lo que se conoce sobre la COVID-19, y también se ha valorado cómo los análisis surgidos de investigaciones científicas han sido adoptados como recomendaciones mundiales, dándole la debida importancia a la validación del conocimiento para establecer estrategias e intentar minimizar los contagios, aplicar los tratamientos más efectivos y seguir en la búsqueda de la vacuna contra esta enfermedad.

Por lo antes expuesto, la producción, publicación y uso de los resultados obtenidos en las investigaciones sobre la COVID-19 es un factor crucial que involucra a investigadores e investigadores como productores del conocimiento y a los sistemas de información científica como los encargados de llevar a cabo su difusión. Así, el objetivo de este escrito es resaltar la contribución de los sistemas de divulgación científica, especialmente de Acceso Abierto, en la construcción del conocimiento sobre el SARS-CoV-2.

\section{Desarrollo}

Para la UNESCO (2020) la ciencia abierta y libre es la clave para luchar contra la COVID-19, debido a que el acceso a los datos y a la información facilita una mejor y más rápida investigación. Pero no solo es la opinión de la UNESCO, se ha observado cómolas grandes editoriales comerciales del mundo (Elsevier, Springer Nature, Portland Press, entre otras), han abierto temporalmente el acceso a la información de forma completa, libre e inmediata, dejando a un lado el modelo de publicación basado en suscripción, para que los resultados de las investigaciones científicas estén disponibles haciendo uso del acceso abierto (Grove, 2020).

Es indudable que este modelo de acceso abierto a la información científica avalada y homologada por pares, respaldada por tecnología de punta para el manejo, almacenamiento y recuperación de la información, se hace primordial en el contexto de la actual pandemia. Es aquí donde los sistemas latinoamericanos de información científica como Redalyc, AmeliCA y SciELO han puesto en marcha proyectos para construir redes de conocimiento y facilitar el acceso a la información apoyando a la comunidad científica. Redalyc, patrocinado por la UNESCO (2020), participa junto con el Instituto de Estadística de la India (ISI) en el desarrollo del Portal de Recursos Universales COVID-19 (CURE - Covid-19 Universal. Resource Gateway, 2020), el cual es una plataforma que recopila información publicada en abierto en revistas, repositorios o bases 
https://doi.org/10.15359/ree.24-S.6

de datos, verificada y autorizada y que trata sobre el ciclo de vida de la pandemia procedente de diferentes fuentes, facilitando a la comunidad científica el acceso a datos e información pertinente y precisa sobre el virus y su propagación.

Por su parte, el índice de revistas en consolidación AmeliCA (2020), construyó la Base de Conocimientos en Epidemias/Pandemias, llevando a cabo una diseminación semántica sobre información especializada en epidemiología, pandemias y temas relacionados. Dicha base de conocimientos se generó a partir de la ejecución de un algoritmo de Inteligencia Artificial basado en ontologías, usando más de 6 mil artículos en formato de Linked Open Data (LOD) que a través de un navegador de contenido permite el acceso a artículos científicos a texto completo publicados en Redalyc y AmeliCA, permitiendo que sean procesados e interconectados en la nube del conocimiento LOD.

Por otro lado, SciELO recopiló una lista de los más recientes documentos disponibles en SciELO preprints y de los artículos sobre la COVID-19 que han sido publicados en cualquier revista científica perteneciente a la Red SciELO.

\section{Conclusión}

Durante esta nueva situación de pandemia, se ha observado la importancia que tiene la actividad de las personas investigadoras en la búsqueda de soluciones a las problemáticas que afectan a la sociedad en general, pero dicha actividad no tendría los mismos frutos si quien investiga no cuenta con los recursos necesarios, de manera que pueda dar respuestas rápidas y precisas con sólidos fundamentos científicos. Por esto, la relevancia de tener acceso abierto, libre y gratuito a los resultados de otras investigaciones que permitan construir redes de conocimiento, participar en el diálogo científico y obtener resultados que aporten beneficios a la sociedad. Es aquí donde los expertos en el manejo y difusión de datos e información deben aplicar las mejores tecnologías y facilitar a los interesados mecanismos de búsqueda, organización y consulta de la información científica disponible en la actualidad, ya que sin estos mecanismos se perdería tiempo valioso que, en el caso de esta pandemia, se traduce en la pérdida de vidas humanas.

Nota general: La traducción y corrección de estilo han sido realizados por la autora y el autor. 
https://doi.org/10.15359/ree.24-S.6

https://www.revistas.una.ac.cr/index.php/educare

educare@una.ac.cr

\section{Referencias}

AmeliCA. (2020, marzo). Base de conocimiento en epidemias/Pandemias de revistas en Amelica/ Redalyc. http://amelica.org/epidemics/

CURE - Covid-19 Universal. Resource Gateway. (2020). COVID-19 Indian scenario. https://drtc. isibang.ac.in/okp/home

Grove, J. (15 de mayo, 2020). Open-access Publishing and the Coronavirus [Mensaje en un blog]. INSIDE HIGHER ED. https://www.insidehighered.com/news/2020/05/15/coronavirus-maybe-encouraging-publishers-pursue-open-access

UNESCO. (2020). Open access to facilitate research and information on COVID-19 [Mensaje en un blog]. UNESCO, Building peace in the minds of men and women. https://en.unesco.org/ covid19/communicationinformationresponse/opensolutions 